\title{
DIGNIDAD HUMANA. RECONOCIMIENTO Y OPERACIONALIZACIÓN DEL CONCEPTO
}

\author{
Monique Pyrrho*, Gabriele Cornelli**, Volnei Garrafa***
}

\begin{abstract}
Resumen: La dignidad humana, presente en la Declaración de los Derechos Humanos e incluso en recientes declaraciones internacionales sobre bioética, recibió últimamente duras críticas como referente bioético. El uso impreciso del término "dignidad", sin una clara definición, al ser atribuido al individuo como valor innato y desvinculado de sus referencias culturales, culmina en su sustitución por un concepto más claro y operacional: el de “autonomía”. El presente trabajo enfrenta la cuestión conceptual de la dignidad humana como construcción relacional que se obtiene mediante el reconocimiento del otro. De esta manera, este término, más amplio y móvil históricamente que el concepto principialista de autonomía, incorpora en su definición y operacionalización las diversidades individuales, sociales y culturales.
\end{abstract}

Palabras clave: dignidad humana, autonomía, bioética, derechos humanos

\section{HUMAN DIGNITY. CONCEPT ACKNOWLEDGEMENT AND OPERATIONALIZATION}

Abstract: Human dignity, present in the Declaration of Human Rights and also in recent international declarations on bioethics, has currently received harsh criticism as a bioethical term. The imprecise use of the term "dignity", without a clear definition, attributed to the individual as innate value and disconnected from its cultural references, culminates in its substitution for a clearer and operational concept: that of "autonomy". This work confronts the conceptual question of human dignity as a relational construction that is obtained through the acknowledgement of the other. In this manner this term, more ample and mobile historically than the principal concept of autonomy, incorporates in its definition and operationalization individual, social and cultural diversity.

Key words: human dignity, autonomy, bioethics, human rights

\section{DIGNIDADE HUMANA: RECONHECIMENTO E OPERACIONALIZAÇÃO DO CONCEITO}

Resumo: O conceito de dignidade humana presente na Declaração dos Direitos Humanos e inclusive em recentes declarações internacionais de bioética, ganhou últimamente duras críticas como referencial bioético. O uso impreciso do termo "dignidade", sem uma clara definiçáo, ao ser atribuido ao indivíduo como valor inato e desvinculado de seus referenciais culturais, culmina com sua substituiçáo por um conceito mais claro e operacional de "autonomia". O presente trabalho enfrenta a questão conceitual da dignidade humana como construção relacional que se obtêm mediante o reconhecimento do outro. Desta maneira, este termo, mais amplo e históricamente móvel que o conceito principialista de autonomia, incorpora em sua definição e operacionalização as diversidades individuais, sociais e culturais.

Palavras chave: dignidade humana, autonomia, bioética, direitos humanos

* Especialista en Bioética. Investigadora de la Cátedra UNESCO de Bioética, Universidad de Brasilia, Brasil

** Doctor en Filosofía. Profesor Adjunto de la Universidad de Brasilia. Investigador de la Cátedra UNESCO de Bioética, Brasil

*** Doctor en Ciencias. Profesor Titular de la Universidad de Brasilia. Investigador de la Cátedra UNESCO de Bioética, Brasil Correspondencia: monique@unb.br 


\section{Introducción}

La dignidad humana se ha convertido en un problema. No sólo desde el punto de vista práctico, político y social, como un principio para definir o para alcanzar en las más diferentes situaciones en que la humanidad encuentra sus límites, sino especialmente en la definición filosófica y bioética y en su operacionalidad como concepto.

La Declaración Universal sobre Bioética y Derechos Humanos ubica a la dignidad humana como un referencial ético central para la ciencia y la tecnología y dice que debe ser respetada en su totalidad(1). Sin embargo, la tan frecuente referencia a la dignidad humana como un principio en diferentes constituciones nacionales y declaraciones internacionales sobre bioética, como un valor fundamental que legitima los demás principios en vez de ampliar su aceptación, está creando cuestionamientos sobre la fundamentación de dicho principio $(2,3)$.

Son frecuentes los discursos en los cuales el recurso a la dignidad humana parece presuponer un entendimiento general sobre el contenido del principio, sin que se haga necesaria su definición(2). En último análisis, esta suposición prescinde del reconocimiento de la diversidad de fundamentaciones teóricas, usos e implicaciones que pueden ser atribuidos a este concepto.

Actualmente, los principales cuestionamientos al concepto residen en la creciente respuesta de una reflexión ontológica del hombre en perjuicio de un enfoque más sociológico y relacional. En ese sentido, una concepción de la dignidad que pretende ser universal y que también se basa en un carácter individual del hombre recibe severas críticas.

Frente a los cuestionamientos apuntados, la relevancia del uso de la dignidad en el interior de la reflexión bioética fue vehementemente negada por algunos autores. El editorial de Ruth Macklin en el British Medical Journal, con el título bombástico de "Dignidad es un concepto inútil”, suscitó mucha polémica y diversas reacciones. Discurriendo sobre la posibilidad de una perfecta sustitución de la dignidad por otro concepto más útil y operacional -la autonomía-, sin pérdida significativa, esa autora cuestiona cómo el uso basado en el impacto emocional de un concepto tan vago e impreciso podría contribuir para discusiones importantes en bioética(4).
Tales afirmaciones no quedaron sin respuesta. Varios bioeticistas respondieron a las críticas a ese fundamento tan apreciado por ellos. Sin embargo, ninguno de esos intentos parece haber sido suficientemente contundente como para, de hecho, elevar justificadamente la dignidad a una posición central en el discurso bioético. No obstante, no es pequeño el riesgo de que ese principio sea eliminado de la reflexión y de la práctica cotidianas.

De alguna forma, las intervenciones críticas a la propuesta de Macklin parecen no alcanzar el efecto deseado con la defensa del concepto de dignidad, por el hecho de que ninguna de ellas contempla la radicalidad de la crítica y el necesario cambio de perspectiva sobre el tema que el editorial impone.

\section{La actualidad del concepto}

La discusión, que ganó dramaticidad en los últimos años, sobre los patrones éticos de la investigación biotecnocientífica, tan alejada de la inicialmente proclamada neutralidad, se dirige hacia la intensificación de la búsqueda por parámetros éticos más palpables. Sin embargo, la evaluación ética instrumentalizada por el uso de principios, descartando conceptos más amplios y plurales como la dignidad, puede conducir a una lectura codificada que termine por anquilosar y reducir la discusión a aplicaciones simplistas de un principialismo neutral y aséptico desde el punto de vista social(5).

Por otro lado, es innegable que la dignidad, como atribución innata y común a todos los seres humanos, estructura la construcción teórica de los Derechos Humanos. Sin la referencia a la dignidad humana éstos serían impensables como derechos universales e inalienables. Empero, este concepto, considerado inicialmente como de carácter innato, pasa a ser una concepción de reconocimiento colectivo de una herencia histórica de civilización(6).

La gran amplitud del término, su carácter orgánico en el contexto de la definición de los Derechos Humanos Universales y el deseo autoidentitario de culturas enteras y sistemas valorativos que encuentran en el término una síntesis de su ética(7) son objeto de críticas como la de Macklin. Según la autora, estos aspectos hacen que en la práctica el principio no sea útil en el enjuiciamiento de casos particulares(4). 
En la literatura se encuentran actualmente dos soluciones para la presente problematización, que llamaremos aquí "culturalista" y "negativista", respectivamente. Según la primera, el concepto de dignidad humana no contempla la diversidad cultural. Como ejemplo de la posibilidad de un abordaje divergente de la individualista, arraigada en la construcción de ese concepto, algunas comunidades étnicas -como es el caso de algunas naciones indígenas brasileñas- subordinan el individuo y su supuesta inalienable dignidad al interés colectivo, a sus intercambios sociales y reconocimientos culturales.

La visión negativista, que pretende salvar el concepto, no escapa de la misma tentación de universalidad al proponer una construcción y abordaje de la dignidad en forma negativa, o sea, partiendo de la percepción de lo que no es digno, negando así "la banalización del mal", la falta de respeto "por la condición única y elevada que el ser humano posee" (6). Con todo, lo negativo de la dignidad adquiere las mismas características universales de esta última, no consiguiendo de este modo responder a las críticas culturalistas.

El debate ya muestra por lo menos una consecuencia: la aparente complejidad del término y las incertidumbres operacionales indicadas conducen a su gradual abandono. Esto se puede ver en las propuestas de su sustitución por la autonomía y por la exclusión del término "dignidad humana" de la edición de 1995 de la Encyclopedia of Bioethics(8), aun cuando estuviera en la edición anterior, de 1978.

Aunque existan indicaciones de una cierta fatiga de la literatura bioética en este debate, nos parece que la discusión sobre el concepto y su operacionalidad no es, ni mucho menos, inútil.

\section{Historia y discusión del concepto}

En su principal crítica al concepto de dignidad, Macklin revela el núcleo central de la construcción del concepto, objeto de amplias y profundas discusiones en la filosofía occidental: "The concept of human dignity (...) is nothing more than a capacity for rational thought and action, the central features conveyed in the principles of respect for autonomy" (4).

En este punto se puede encontrar una identificación entre dignidad y capacidad de acción racional, algo que acompaña todo el camino del pensamiento occidental sobre ese término.
A su vez, Kant recupera el concepto de dignidad humana ya no con una fundamentación religiosa, pero sí como atribución de la razón(9). Al establecer que el hombre posee un valor no-relativo, intrínseco, sin equivalencia y, por lo tanto, insustituible, fundamenta la dignidad como consecuencia de esa insustituibilidad del ser humano racional, siempre fin en sí mismo(10).

La etimología de esa palabra deriva del latín dignitas, prerrogativa de la nobleza romana. Ese término designaba características como la autodeterminación y el decoro, y también postulaba atribuciones sociales y respeto. Ambos significados relacionados con poder y superioridad(11).

Una búsqueda por la historia de la actual acepción de "dignidad" revela una contradicción que, de alguna forma, debe ser enfrentada también desde las críticas de Macklin: si la dignidad se basa en la capacidad de acción racional del hombre y por tanto en su autonomía, ¿no sería realmente posible su sustitución? Si debemos basarnos en el respeto a la autonomía, caracterizada por la razón y por la capacidad de actuación según ésta, ¿cómo proceder con relación al ser humano limitado aunque sea temporalmente en alguna de esas dimensiones?

Kant no parece solucionar esa cuestión, puesto que fundamenta sobre la autonomía de la voluntad un concepto que pretende - por sí mismo- tener una objetividad y una universalidad más grandes.

Tampoco las críticas al carácter individualista del concepto de dignidad son respondidas con su sustitución por el de autonomía. Aunque sea posible afirmar un carácter menos impreciso de esta última, la pretensión universalista o el fuerte cuño individualista no son eliminados con la sustitución. Por el contrario, cuando se entiende que la dignidad se construye y se realiza por el reconocimiento, como propone Hegel en la "Dialéctica del señor y del esclavo"(12), y no por el respeto, como en Kant, se puede percibir que es mediante la relación con el otro y sólo en ese reconocimiento recíproco que la dignidad se establece(13). En cuanto en el primero el respeto a la autonomía de uno puede derivarse de la limitación de los demás, caracterizando una valorización de lo individual, para el segundo el reconocimiento de un otro igualmente digno, aunque no igualmente autónomo, sólo se puede entender como una consideración por la colectividad construida en el ámbito de las relaciones. 
Por otro lado, la naturalización de la dignidad humana, de raíz aristotélica y posteriormente cristiana, según la cual la dignidad es innata, no parece sostenerse frente a las críticas de una visión culturalista y no religiosa de la ética y del ser humano.

Es así que, en medio de esas contradicciones, emerge el cuestionamiento central que ofrece un norte al camino de recuperación de un sentido para el concepto y para su operacionalidad en bioética.

La propia etimología del término "dignitas" y el uso antiguo parecen apuntar hacia un camino: dignidad no como algo innato, pero resultado de una atribución social de lo que constituye el minimum innegociable. De ese modo, dentro de una determinada cultura, la dignidad correspondería a un estatus, con su poder, derechos, privilegios, exigencias y obligaciones propias de un papel social(14). A partir de una formación individual esencialmente dialógica, de construcción de la identidad a partir del otro, la dignidad emerge como un concepto relacional, no ontológico o lógico, sin que se pueda predicar del ser humano en cuanto tal o que derive lógicamente de su capacidad racional. De forma más significativa, la dignidad es algo que se construye en el interior del tejido cultural de las relaciones materiales y simbólicas(7).

En su carácter ontológico o religioso original, la dignidad no sirve como parámetro para demarcar concretamente las cuestiones éticas actuales sobre la vida humana, a no ser que en su concreción como principio resida otra comprensión que la descentralice del individuo y la reponga en la base de las relaciones, para que en ellas se constituya y alimente.
La dinámica de las relaciones, principalmente las que se caracterizan por su vulnerabilidad, denota el carácter no desechable de un concepto como el de dignidad, que busca tener un alcance colectivo y sustancialmente relacional, importante para contextos marcados por la desigualdad social. Supera pues a la autonomía en la protección de los sujetos, por contemplar dimensiones humanas como el autogobierno y, más que eso, la responsabilidad moral con relación al otro, algo fundamental en las relaciones intersubjetivas(15).

\section{Conclusión}

Es a este concepto operacional y relacional que la bioética puede hacer referencia de forma útil. De ese modo, aunque Macklin tiene razón en criticar el lado emocional del término, no se puede aceptar cambiarlo por una autonomía aséptica. La dignidad es un concepto mucho más complejo culturalmente y dinámico históricamente que la principialista autonomía.

Obviamente, un concepto así construido no permite definiciones cartesianas, claras y distintas. Pero ya Ludwig Wittgenstein se preguntaba: ¿"Será siempre ventajoso cambiar un retrato poco claro por otro bien nítido? ¿No será el retrato poco nítido exactamente lo que necesitamos?”(16). Parece que sí. Es de este concepto de dignidad que todavía tenemos necesidad. Un concepto que, por ser más rico en sedimentaciones éticas y soluciones morales, aun en sus contradicciones, constituye una reserva insustituible de estrategias de valorización del ser humano en sus más diferentes contextos.

\section{Referencias}

1. United Nations Educational, Scientific and Cultural Organization (UNESCO). Universal Draft Declaration on Bioethics and Human Rights. SHS/EST/05/CONF.204/3REV. Paris: UNESCO; 24 June 2005.

2. Häyry M, Takala T. Human dignity, bioethics and human rights. Developing World Bioethics 2005; 5(3): 225-233.

3. Häyry M. Another look at dignity. Cambridge Quarterly of Healthcare Ethics 2004; 13(1): 7-14.

4. Macklin R. Dignity is a useless concept. British Medical Journal 2003; 327(7429): 1419-1420.

5. Garrafa V, Porto D. Intervention Bioethics: a proposal for peripheral countries in a context of power and injustice. Bioethics 2003; 17(5-6): 399-416.

6. Barchifontaine CP. Bioética e início da vida: Alguns desafios. São Paulo: Idéias e letras; 2004: 19-31.

7. Oliveira Mendes JM. Solidamente ancorados: a dignidade e o reconhecimento como recursos identitários. In: IV Congresso Português de Sociologia: Passados Recentes, Futuros Próximos. Braga; 2004. Sitio en Internet. Disponible en http://www. aps.pt/desdobra.htm

8. Reich WT. Encyclopedia of Bioethics. 2 ed. New York: Macmillan; 1995. 
9. Abbagnano N. Dicionário de Filosofia. São Paulo: Martins Fontes, 1998: 276-277.

10. Kant I. Fundamentaçâo da Metafísica dos Costumes. Porto: Ediçôes 70; 1995.

11. Fabri dos Anjos M. Dignidade humana em debate. Bioética 2004; 12(1): 109-114.

12. Hegel CF. Fenomenologia do Espirito. Rio de Janeiro: Vozes; 2002: IV a.

13. Rosemfeld D. Hegel. Rio de Janeiro: Zahal; 2002: 51.

14. Adler F. Human dignity and social science. Sociological inquiry 1963; 33(1):9-18.

15. Rendtorff JD. Basic ethical principles in European bioethics and biolaw: Autonomy, dignity, integrity and vulnerability - Towards a foundation of bioethics and biolaw. Medicine, Healthcare and Philosophy 2002; 5(3): 235-244.

16. Wittgenstein L. Investigaçóes filosóficas. Rio de Janeiro: Vozes; 2005: 71.

Recibido: 12 de agosto de 2008

Aceptado: 25 de septiembre de 2008 